\title{
Brenda Piselli, Metamorfosi dell'“Amphitruo" attraverso i secoli
}

\section{Ida Merello}

\section{Q OpenEdition}

1 Journals

\section{Edizione digitale}

URL: http://journals.openedition.org/studifrancesi/7028

DOI: $10.4000 /$ studifrancesi.7028

ISSN: 2421-5856

\section{Editore}

Rosenberg \& Sellier

\section{Edizione cartacea}

Data di pubblicazione: 1 septembre 2010

Paginazione: 406

ISSN: 0039-2944

\section{Notizia bibliografica digitale}

Ida Merello, "Brenda Piselli, Metamorfosi dell"'Amphitruo" attraverso i secoli», Studi Francesi [Online], 161 (LIV | II) | 2010, online dal 30 novembre 2015, consultato il 08 janvier 2021. URL: http:// journals.openedition.org/studifrancesi/7028; DOI: https://doi.org/10.4000/studifrancesi.7028

Questo documento è stato generato automaticamente il 8 janvier 2021.

\section{(c) (i) (9)}

Studi Francesi è distribuita con Licenza Creative Commons Attribuzione - Non commerciale - Non opere derivate 4.0 Internazionale. 


\title{
Brenda Piselli, Metamorfosi dell'"Amphitruo" attraverso i secoli
}

\author{
Ida Merello
}

\section{NOTIZIA}

BRENDA PISELLI, Metamorfosi dell'“Amphitruo” attraverso i secoli, Genova, Tilgher, 2009, pp. 348.

1 Il volume, imponente per l'arco letterario che abbraccia e per la bibliografia, si incentra sul mito di Anfitrione, con una trattazione estremamente accurata: l'A. sottolinea i dati salienti della fortuna del mito di Anfitrione attraverso un'analisi fondata non solo su pièces che costituiscono le tappe fondamentali nella storia dell'evoluzione del mito, ma anche su opere che, abitualmente non associate alla fabula di Anfitrione, contribuiscono invece a illuminarne i principali aspetti (Avatar di Gautier, Il ritorno di Casanova di Schnitzler, Hélas pour moi di Godard). In particolare, la monografia ripercorre la storia delle pièces francesi (Rotrou, Molière, Jean e Jean-Pierre Giraudoux, André Arcellaschi), con interesse specifico alle fonti, alla struttura, ai personaggi, al linguaggio e alla teatralità delle rielaborazioni. In appendice, è posta la prima traduzione italiana di Amphitryon 39 di Jean-Pierre Giraudoux.

2 L'A. dimostra che, in Amphitryon 38, la sceneggiatura plautina, rispettata nelle sue linee essenziali fino a Molière e reperibile ancora in Dryden e in Kleist, è assente, poiché Alcmena assurge a protagonista della pièce e Anfitrione non appare nelle scene di cui i precedenti rifacitori lo avevano reso protagonista: Anfitrione non è il marito tradito e geloso della tradizione, ma uno sposo premuroso e un perfetto uomo di casa; Giove non è un dio autocrate e sicuro di sé, ma un dio innamorato, che si interroga sulla propria identità; Mercurio vede ridotta la sua funzione di messaggero; il ruolo di Sosia è quasi eliminato e non riveste più una funzione apertamente comica. L'A. sottolinea che, fingendosi l'“altro", cioè Anfitrione, Jupiter vive un'esperienza "schizofrenica"; il ruolo di Amphitryon è soffocante per Jupiter, siccome impedisce al dio di essere riconosciuto 
e amato per se stesso, come dimostra la distinzione fra marito e amante, espressione della "ferita narcisistica" del dio.

3 L'A. riserva infine ampio spazio ad Amphitryon 39, nel quale i dati del mito sono deliberatamente alterati, attraverso un progressivo ribaltamento delle parti. Tuttavia, rispetto al padre, che ha rovesciato l'ottica di Alcmena, perché l'eroina è informata in precedenza da Mercurio della visita di Giove, Jean-Pierre Giraudoux si spinge oltre, dimostrando una tendenza a umanizzare la figura di Giunone e ad arricchire il mito di nuovi giochi di specchi: dal momento che il ruolo ricoperto nelle precedenti riscritture da Giove è qui assunto da Giunone, che veste i panni di Alcmena, in luogo del confronto tra i due Anfitrioni (presente nei rifacimenti basati sulle scenae suppositiciae dell'Amphitruo), compare il confronto tra due Alcmene.

4 In sintesi, il volume, completo sotto tutti gli aspetti, testimonia l'attualità del mito di Anfitrione, la cui natura sfuggente introduce oggi, come in passato, problematiche di difficile risoluzione, contribuendo a ridisegnare costantemente gli incerti confini del genere comico. 